\title{
ANALISA KERJA RECLOSER UNTUK MEMPROTEKSI JARINGAN DISTRIBUSI DI PT. PLN (PERSERO) AREA SORONG
}

\author{
Alimuddin, ST., MT. \\ Jurusan Teknik Elektro \\ Politeknik Katolik Saint Paul Sorong \\ ghailan11@rocketmail.com
}

\begin{abstract}
Abstrak
Gangguan yang terjadi sering bersifat sementara, ini penggunaan circuit breaker dirasa kurang efesien, dengan itu digunakan peralatan pengaman recloser yang dapat membuka (open) secara automatis bila ada gangguan, jika kondisi sudah normal akan menutup (close) kembali. Operasi membuka dan menutup kembali dari recloser dapat terjadi beberapa kali sesuai dengan setting yang ditentukan operator.

Dengan aplikasi WinSMART GRID kita dapat mengetahui Recloser status kontrol, metering, dan sinyal. Hal ini menunjukan bahwa sistem kerja Recloser di PT PLN ( Persero ) Area Sorong sudah otomisasi.
\end{abstract}

Kata kunci : Recloser, WinSMART GRID, otomisasi

\section{PENDAHULUAN}

Dengan melihat perkembangan teknologi di dunia, segala pekerjaan dilakukan dengan cepat, tepat, dan sesuai dengan target. Ini merupakan suatu hal yang sangat diinginkan oleh manusia itu sendiri. Mari kita lihat salah satu perkembangan teknologi dalam mengantisipasi suatu gangguan jaringan distribusi PT PLN (Persero) Area Sorong. Teknologi yang digunakan yaitu Alat Proteksi yang bernama Recloser.

Recloser merupakan suatu peralatan pengaman yang dapat mendeteksi arus lebih karena hubung singkat antara fasa dengan fasa atau fasa dengan tanah, dimana recloser ini memutus arus dan menutup kembali secara otomatis dengan selang waktu yang dapat diatur misal dengan pengaturan interval reclose 1 sampai 5 detik dan setting interval reclose 2 sampai 10 detik dan pada trip ketiga recloser akan membuka tetap dengan sendirinya karena gangguan itu bersifat permanen. Peralatan ini digunakan sebagai pelindung saluran distribusi dan mempunyai peranan penting dalam perlindungan sistem daya karena saluran distribusi merupakan elemen vital suatu jala-jala, yang menghubungkan gardu ke pusat - pusat beban. Dengan memanfaatkan teknologi ini PT. PLN (Persero) dapat memberikan pelayanan yang terbaik untuk konsumen sehingga nama baik PT. PLN (Persero) dan kepercayaan konsumen akan semakin meningkat.

\section{TINJAUAN PUSTAKA}

\subsection{RECLOSER}

Dalam distribusi tenaga listrik, recloser, atau autorecloser, adalah pemutus sirkuit yang dilengkapi dengan mekanisme otomatis yang dapat menutup setelah terjadi suatu kesalahan yaitu trip Recloser digunakan pada SUTM untuk mendeteksi dan menanggulangi jika terjadi kesalahan sesaat. 
1. Vacuum interrupter

2. Push rod - insulating

3. Actuator

4. Epoxy housing

5. Silicone bushing extension

6. Terminal

7. Tank

8. Auxilary switches

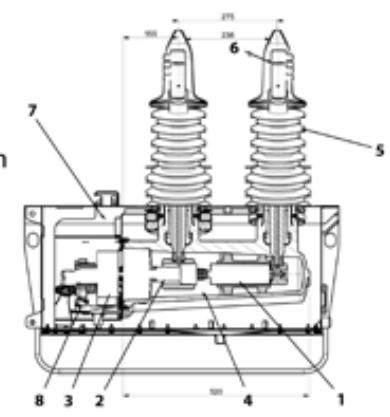

Gambar 2.1 Lay Out Recloser

Untuk mencegah kerusakan, setiap sepanjang jaringan dilindungi dengan pemutus arus seperti recloser ini yang akan mematikan listrik jika terjadi hubungan pendek.

\subsection{Konstruksi Recloser Entec EVRC 2A}

Didalam laporan ini saya sebagai penulis akan membahas recloser yang bermerk Entec dengan tipe EVRC 2A.

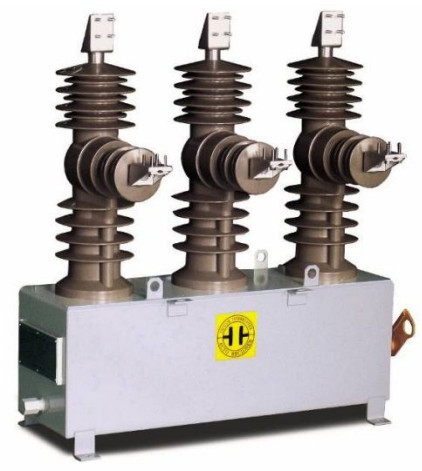

Gambar 2.2 Recloser Entec EVRC $2 A$

Entec EVRC 2A adalah salah satu recloser yang dipakai PT PLN ( Persero ) Area Sorong sebagai pengaman arus hubung singkat. Entec EVRC 2A dirancang untuk tegangan AC 110/220V untuk jalur distribusi tegangan rendah. Entec EVRC 2A terdiri dari terisolasi kerangka epoxy, tangki logam, dan kubikel untuk kontrol.

Tabel 2.1 Dimensi Entec EVRC 2A

\begin{tabular}{|l|l|l|l|l|}
\hline $\mathbf{k V}$ & $\mathbf{A}$ & $\mathbf{B}$ & $\mathbf{C}$ & $\mathbf{D}$ \\
\hline $27 \mathrm{kV}$ & 650 & 350 & 885 & 310 \\
\hline
\end{tabular}

Tabel 2.2 Standar Entec EVRC 2A

\begin{tabular}{|c|c|}
\hline Tegangan Maksimal Sistem & $27 \mathrm{kV}$ \\
\hline Rating Frekuensi & $50 / 60 \mathrm{~Hz}$ \\
\hline Rating Arus kontinu & $630 \mathrm{~A}$ \\
\hline Rating arus hubung singkat & $12.5 / 16 \mathrm{kA}$ \\
\hline Rating makingcurrent & $32.5 \mathrm{kA}$ (peakvalue) \\
\hline Powerfrequencywithstandvol tage & \\
\hline -dry & $60 \mathrm{kV}(1 \mathrm{~min})$ \\
\hline -wet & $50 \mathrm{kV}(10 \mathrm{sec})$ \\
\hline Ratedimpulse withstandvoltage & $150 \mathrm{kVBIL}$ \\
\hline Mechanicaloperationlife & 10,000 operations \\
\hline Auxiliarypowersupply & AC110/220Vexternalpowersources \\
\hline Kontrolcircuitvoltage & $\mathrm{DC} 24 \mathrm{~V}$ \\
\hline Protectioncurrenttransformer(CT)ratio & $1000: 1 \mathrm{~A}$ \\
\hline \multicolumn{2}{|l|}{ Weight } \\
\hline -maintank & $160 \mathrm{~kg}$ \\
\hline -kontrolcubicle & $84 \mathrm{~kg}$ \\
\hline
\end{tabular}

Recloser dapat dipasang pada tiang di luar ruangan dengan merakit mounting bracket yang terhubung dengan pagar logam yang ada di atas tiang dan juga dipasang dengan box mounting yang terpisah.Pemutus vakum, penggerak magnetik, dan trafo arus (CT) yang ada di circuit breaker.

Pemutus recloser didisain untuk tegangan 3fasa dengan isolasi lengkap yang dipasang di kerangka epoxy yang terisolasi dan dioperasikan oleh $\underline{\operatorname{Rod}}$ isolasi yang sama. Isolasi Rod terhubung pada ujung kontak transfer dengan kekuatan penggerak dari actuator magnetik ke pemutus untuk operasi tutup dan buka.

Tigabox isolasi yang berada di atas pagar logam ini terbuat dari resin epoksi sikloalifatik. Transformator arus (CT) yang dibentuk dalam kerangka isolasi dan CT dapat memantau arus gangguan yang ada di setiap fasa, gangguan arus grounding dan arus beban, dan dapat mengirim sinyal ke kontrol elektronik yang ada pada kubikel kontrol.

Jika kabel kontrol CT terputus pada kedua ujungnya, CT secara otomatis putus karena diputuskan oleh kontrol otomatis yang melindungi CT.

Manual Trip / Menutup / Perangkat Pengunci berada di sisi depan kubikel kontrol. Indikator menunjukkan statusnya buka / tutup -nya pemutus dan operasinal kontrol terletak di bagian bawah kubikel. 
Urutan pengoperasian recloser dilakukan oleh relay yang berbasis mikroprosesor. Relay dipasang di kubikel kontrol yang mana telah terlindungi oleh pelindung anti hujan. Recloser dengan segera akan melakukan urutan operasi untuk buka-tutup kembali ketika arus gangguan fase / grounding ini lebih tinggi dari nilai yang ditetapkan.

Jika arus gangguan tidak ditangani, maka recloser akantidak bekerja dan akantetap membuka sampai operasi berikutnya. Jika arus gangguan sudah ditanggani, recloser akan menutup, dan kemudian kembali ke modus tidur setelah waktu direset ulang. Ketika arus gangguan terdeteksi, recloser beroperasi kembali secara normal.

Recloser disuplai oleh AC 110/220V atau baterai primer VDC tanpa transformator tambahan, dan dirancang untuk mengkonsumsi energi yang rendah untuk pengoperasian me-reclose dan me-remote.

Jika sumber tegangan tidak tersedia, recloser sudah dilengkapi dengan trafo tegangan tambahan untuk memasok sumber daya tambahan ke kubikel kontrol.Selama operasi membuka dan menutup, relay mengirimkan pulsa arus ke kumparan membuka dan menutup, dan gaya magnetik yang menginduktansi kumparan dan menggerakkan plunger padapenggerak magnetik.

Setting relay pada rangkaian kontrol dapat dimodifikasi di panel kontrol, PC atau metode komunikasi dikendalikan dari jarak jauh.

\subsection{Bagian-Bagian Pada Recloser}

\section{Pemutus}

Pemutus vakum udara pada recloser dapat memberikan fleksibelitas untuk pengoperasian trip / menutup dengan rating dan kapasitas yang ada berdasarkan gangguan yang sering terjadi.

Pemutus vakum sepenuhnya disegel dan hanya membutuhkan kontak kecil.Sangat cocok untuk diaplikasikan di mekanisme penggerak magnetik dan juga pemutus vakum memiliki kemampuan beroperasi, dan sangat ideal untuk diaplikasikan di recloser itu.
Dengan demikian, pemutus vakum dengan penggerak magnetik memberikan kehandalan yang tinggi dalam beroperasi dan pemeliharaannya tidak sulit.

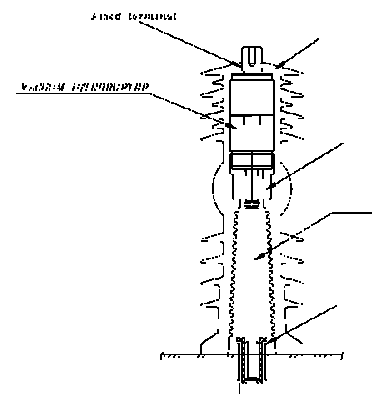

Gambar 2.3 Pemutus pada recloser

\section{Penggerak Magnetik}

Penggerak magnetik dirancang oleh teknologi terbaru memberikan kekuatan untuk pemutus tersebut. Karena penggerak magnetik hanya mengkonsumsi daya yang rendah, operasi mengubah penggerak dapat dilakukan dengan tegangan AC 110 atau 220V dipasok dari sumber daya eksternal dan juga baterai yang terisi dengan sumber tegangan DC.

Mekanisme penggerak magnet hanya memiliki satu bagian yang bergerak. Dengan demikian penurunan bagian dalam memberikan peningkatan yang sesuai dalam kehandalan. Terutama, sebagai penggerak menggunakan magnet yang menempel dan menggunakan kumparan trip dan close secara terpisah, penggerak terdiri dari komponen yang sedikit dan pemeliharaannya tidak terlalu sering.

Rod adalah bahan isolasi berkekuatan tinggi dimana akan memberikan kekuatan untuk pemutus tersebut. Ketika arus pulsa yang mengalir pada kumparan close, plunger penggerak magnetik akan bergerak karena induksi gaya magnetikyang mana akan mendorong pemutus untuk posisi close, dan penggerak kemudian ditahan dalam posisi close. Sebaliknya, ketika pulsa arus mengalir ke kumparan trip, plunger melepaskan kait magnetik dan pemutus tersebut akan berpindah ke posisi trip. 

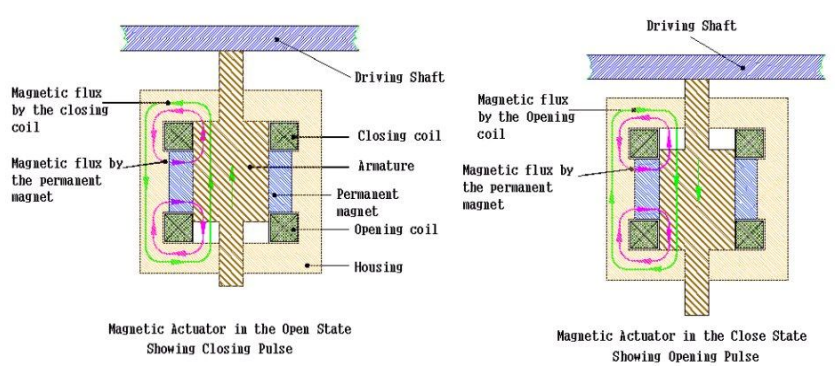

Gambar 2.4 Prinsip magnetic pada operasional penggerak

\section{Box Isolasi}

Kerangka isolasi yang terpasang di bagian atas pagar logam memiliki ketahanan terhadap cuaca, hidrofobik.Box isolasi diproduksi dengan metode cetakan APG dengan menggunakan resin epoxy.

Inti cincin CT yang ada didalam box isolasi dapat merasakan aliran arus. Dimana informasi arus ini ditransmisikan ke relay berbasis mikro-prosesor melalui kabel multi-core. Kapasitor pembagi tegangan (CVD) yang ada di dalam box isolasi adalah untuk mengukur dan merasakan tegangan sekunder untuk sinyal penggunaan.

\section{Manual Trip/ Penutup/ Alat Penguncian.}

Selama ada kesalahan pada sirkuit kontrol atau perbaikan pada jalur, operator dapat langsung mengoperasikan trip/ closing/ locking recloser dengan tuas trip/ closing/ locking yang dapat beroperasi secara manualyang beradapada sisi depan boxnya. Dengan begitu dapat dioperasikan secara manual dengan COS hot stick. Operasi manual tersedia pada tuas trip. Jika tuas trip / locking berada di posisi lock, recloser tidak dapat dioperasikan oleh kontrol lokal / remote karena power penggerak mati.

Dalam posisi lock ini, operator harus mendorong tuastrip / locking ke posisi trip untuk mengembalikan status lock dari recloser dan kemudian recloser dapat dioperasikan oleh kontrol lokal atau remote kembali.

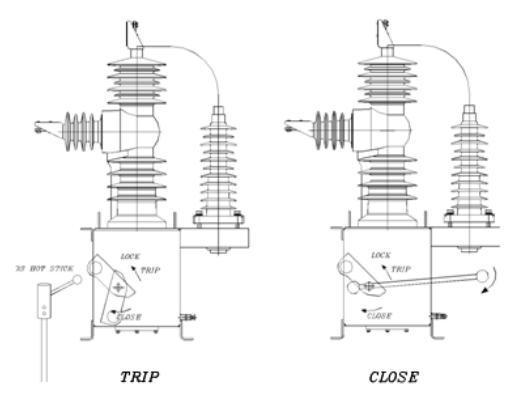

Gambar 2.5 Peralatan Manual Recloserl Trip/ Closing/ Locking

\section{Saringan Molekul}

Saringan molekul diatur untuk menyerap kelembaban dalam box isolasi dan box logam recloser.

Sebuah poliester yang mengandung saringan molekuler ditempatkan di dalam box dan kubikel kontrol.

Saringan molekul biasanya digunakan untuk menghilangkan $\mathrm{H} 2 \mathrm{O}$ dan $\mathrm{CO} 2$ bersamaan dari aliran udara dan menghilangkan $\mathrm{H} 2 \mathrm{~S}$.

Saringan molekul dapat diregenerasikan dengan mengevakuasikan atau membersihkannya, biasanya pada temperatur yang tinggi mulai dari $200{ }^{\circ} \mathrm{C}$ sampai $300^{\circ} \mathrm{C}$.

Namun, karena adanya recloser ini PT. PLN APD Disjata Disjata dapat mengurangi kecelakaan yang diakibatkn oleh arus hubung singkat dan juga kerusakan komponen yang terjadi jika arus hubung singkat tersebut melewati komponen-komponen yang rentan kerusakan. Maka dengan recloser ini arus hubung singkat ini dapat ditanggulangi dan sistem akan segera kembali normal.

\section{Baterai dan Charger Baterai}

Baterai digunakan untuk mengoperasikan komponen recloser dan rangkaian kontrol dimana baterai dan chargernya ditempatkan di bagian bawah kubikel kontrol dan dapat dengan mudah diganti.Masa pakai baterai biasanya 5 tahun, tetapi dapat diperpendek tergantung pada bagaimana baterai itu dipelihara. Baterai yang terisi penuh sudah cukup untuk 30 jam operasi tanpa sumber daya eksternal. 


\section{Kubikel Kontrol}

Kubikel kontrol recloser dirancang untuk dipasang di tiang outdoor dan gardu operasi yang terbuat dari stainless steel anti-korosi.

Pintu dikunci dengan tiga posisi penguncian dirancang dan disegel dengan diganti kemasan busa urhetan.

Semua ventilasi dapat menyaring hama yang akan masuk dan didalam kubikel sepenuhnya ditutupi dengan bahan faming adiabatik yang akan melindungi komponen yang didalam dari variasi suhu yang ada disekitar kubikel.

Kubikel kontrol yang berada diluar dilindungi dengan perisai penutup dari sinar matahari yang akan menjaga siklus kerja dari kubikel karena komponen elektronik sensitif terhadap suhu dan baterai sangat terpengaruh pemanasan sinar matahari.

Kompartemen kontrol berbasis mikroprosesor benar-benar disegel terhadap masuknya air meskipun pintu dibuka dalam kondisi hujan pada saat operasi ataupun pemeliharaan.

Kondensasi di dalam kubikel dapat diharapkan untuk busa karena variasi suhu di bawah kondisi atmosfer seperti iklim tropis, namun kondensasi apapun tidak mempengaruhi komponen elektronik yang diatur sepenuhnya dengan terisolasi dan disegel baik dengan desain vented.

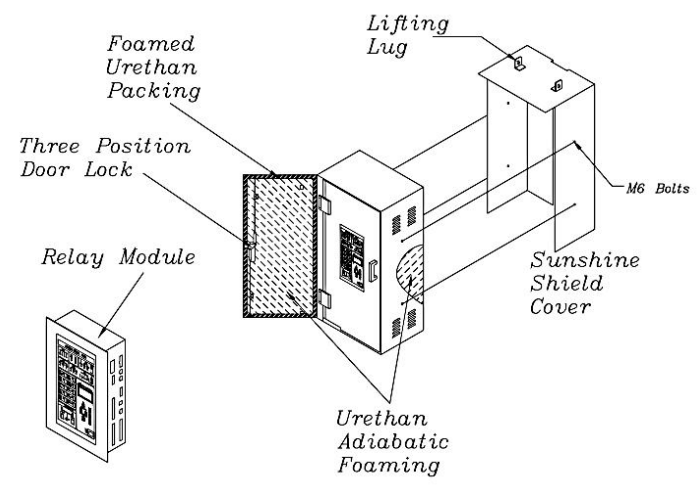

Gambar 2.6 Lay Out Kubikel Kontrol
Konsekuensinya, setiap kondensasi pada permukaan logam akan turun ke bawah dan secara otomatis mengering tanpa mempengaruhi modul elektronik dengan ventilasi dan pemanas yang ada.

Standar kubikel kontrol yaitu berisi relay, baterai untuk daya cadangan dan daya penggerak mekanisme.

Kubikel kontrol tidak harus dipasang di luar ruangan tanpa penutup sinar matahari di tempat terkena sinar matahari.

\section{Suplai Tenaga Tambahan}

a. Dari sumber daya eksternal dari $110 \mathrm{~V}$ dan $220 \mathrm{~V}$ disediakan oleh trafo daya tambahan.

b. Dari suplai tegangan rendah dihubungkan ke jalur distribusi.

c. Selain di atas, lebih banyak menggunakan sumber dari DC $110 \mathrm{~V}$ pasokan dari sumber eksternal atau DC $135 \mathrm{~V}$ baterai primer.

Sebenarnya, pasokan tambahan digunakan untuk mengoperasikan recloser otomatis melalui sirkuit rectifying dan dapat memelihara muatan pada baterai.

Pengoperasian recloser terpenuhi jika pasokan daya tambahan yang melalui rangkaian dilanjutkan ke pengisian baterai.Baterai ini digunakan untuk memback-up operasi dari recloser bila catu daya tambahan hilang.

Baterai ditempatkan di bagian bawah kubikel kontrol dan dapat diatur agar mudah diganti.

Masa pakai baterai diperkirakan digunakan selama 5 tahun layanan seperti yang direkomendasikan oleh produsen baterai, tetapi masa hidupnya baterai dapat dilihat bagaimana dan seberapa sering baterai itu dipelihara.

Baterai cukup untuk 30 jam dan lebih dari 50 event tanpa catu daya eksternal.

Bila baterai hampir habis dan menunjukkan dibawah DC $15 \mathrm{~V}$ ketika baterai diuji dengan beban, silahkan ganti baterai dengan yang baru seperti yang ditunjukkan dalam tabel spesifikasi baterai. 


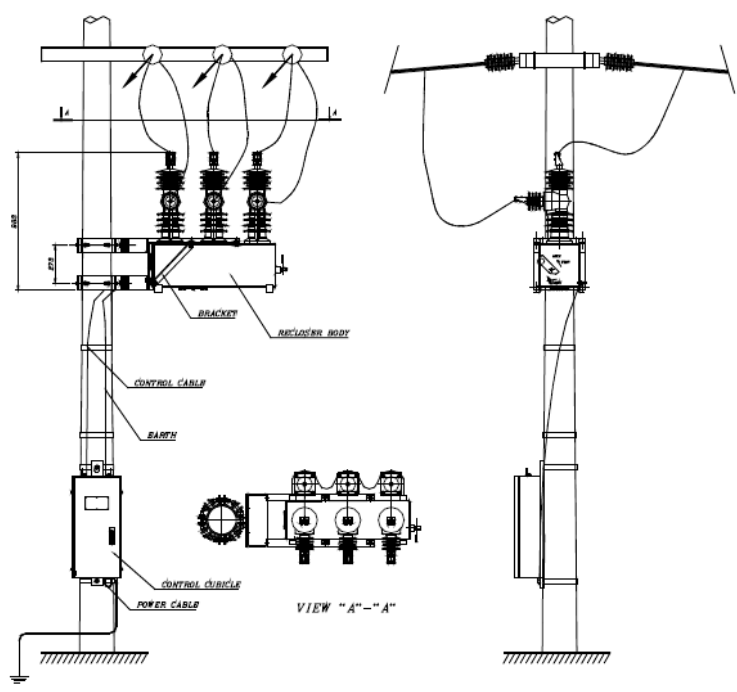

Gambar 2.7 Suplai Tenaga Tambahan

\section{Perancangan Sistem}

Perancangan sistem yang digunakan adalah program yang bernama WinSMART GRID. Berikut manual operation WinSMART GRID

\section{LOGIN}

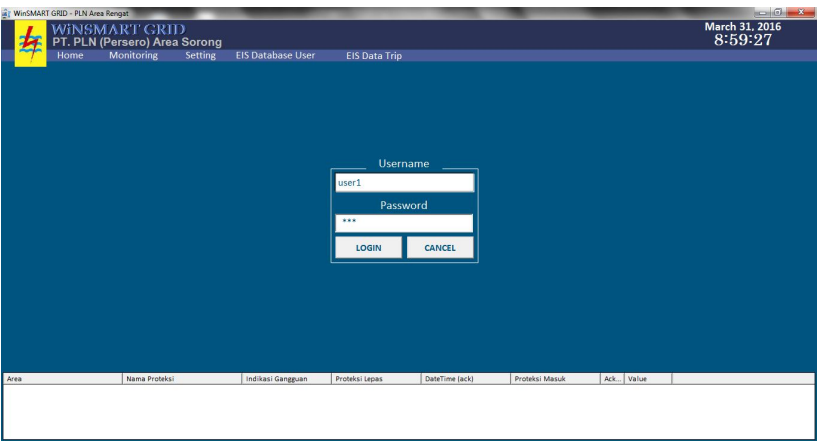

Gambar 3.2 Login

Tampilan ini di fungsikan untuk login dengan memasukkan password yang sudah di tentukan. Fasilitas ini digunakan untuk pengamanan dalam hal pemakaian aplikasi, dengan kata lain aplikasi ini hanya bisa di pakai oleh orang-orang tertentu saja/user.

\section{MONITORING}

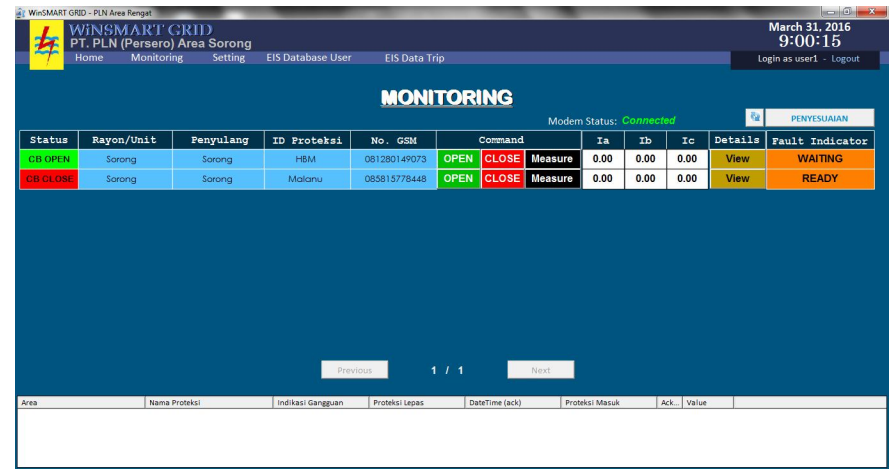

Gambar 3.3 Monitoring

Pada menu Monitoring ini, user dapat memonitoring status pemutus yang ada dilapangan dan dapat mengeksekusinya. Menu ini ditampilkan dalam bentuk tabel yang terdiri dari kolom Status, Rayon/Unit, Penyulang, No. GSM, Command, Ia Ib Ic, Details, dan Fault Indicator.

\section{VIEW DETAIL}

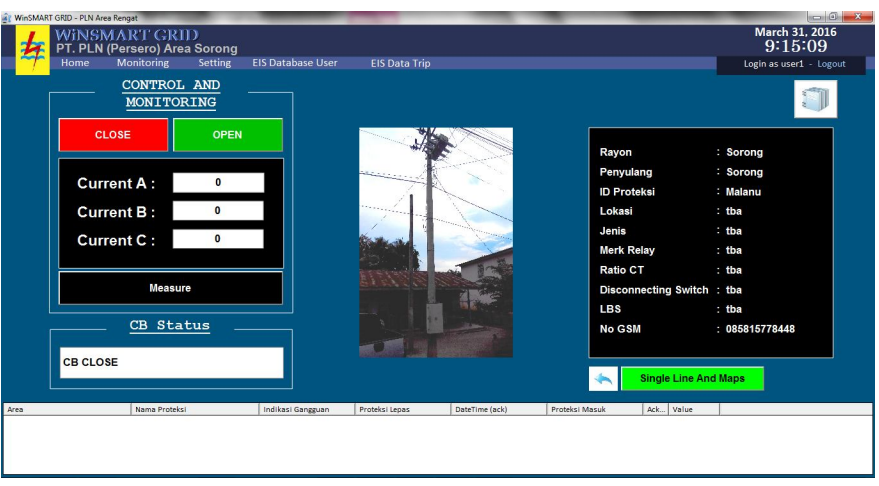

Gambar 3.4 View Detil

Tombol view ini berfungsi untuk melihat informasi detail di dalam setiap recloser. Adapun fasilitas di dalam view ini yaitu tombol open/ close / measure yang sama fungsinya pada bagian tampilan monitoring, single line and maps, dan report. Serta terpampang foto recloser di dalamnya. 


\section{SINGLE LINE AND MAPS}

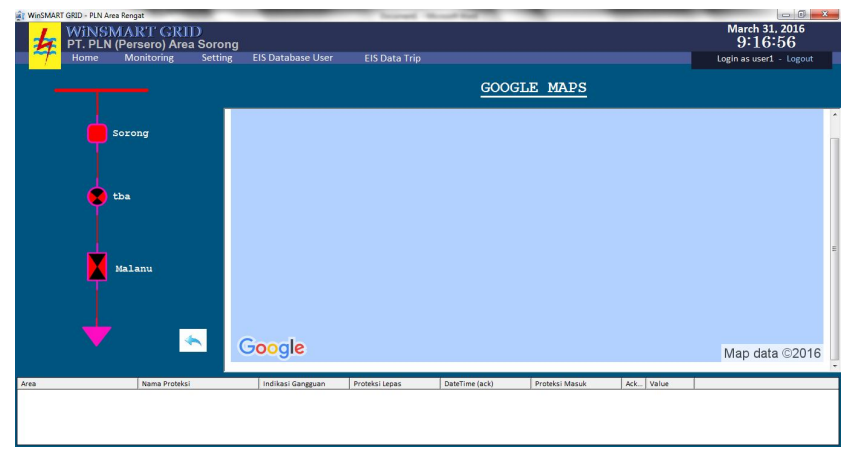

Gambar 3.5 Single Line And Maps

Ditampilkan gambar single line dari Penyulang - LBS

- Recloser, serta tampilan maps untuk mengetahui letak lokasi di setiap recloser.

\section{REPORT}

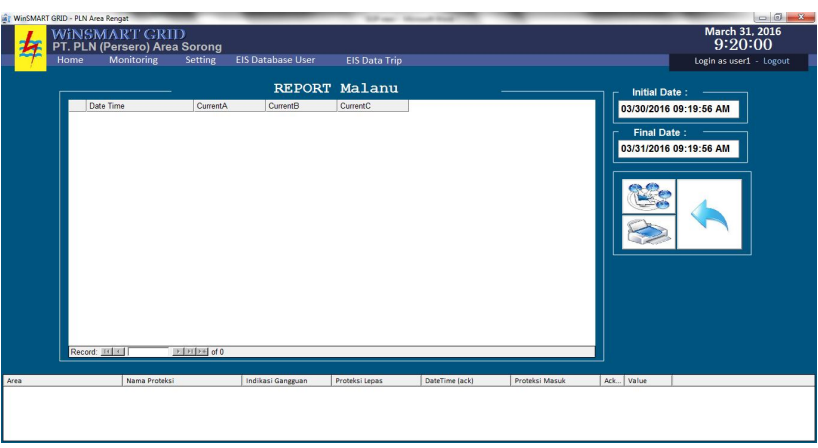

Gambar 3.6 Report

Fungsinya untuk mengetahui kondisi beban sesuai dengan yang kita inginkan, dalam hal ini kita dapat menyesuaikan kondisi beban di setiap recloser dari tanggalnya, terus tekan tombol query untuk menampilkan kondisi beban di tabel report.

\section{HOME}

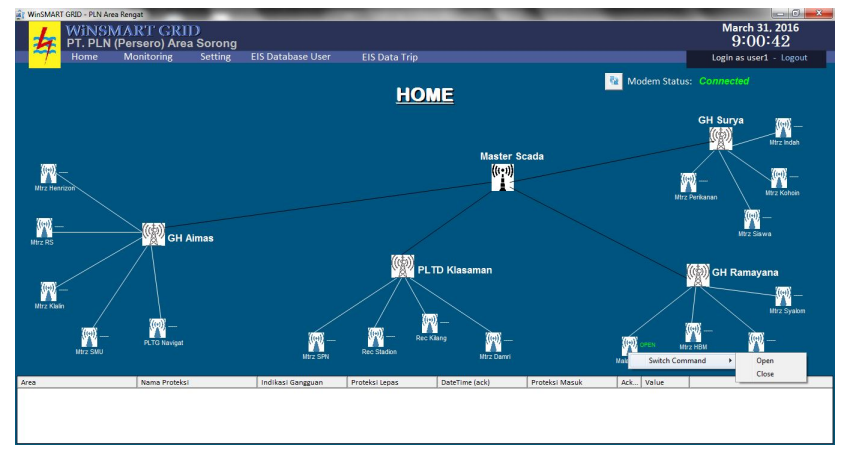

Gambar 3.7 Home
Pada halaman ini, terdapat gambaran system

konfigurasi pada Scada Sorong

\section{RAYON SETTING}

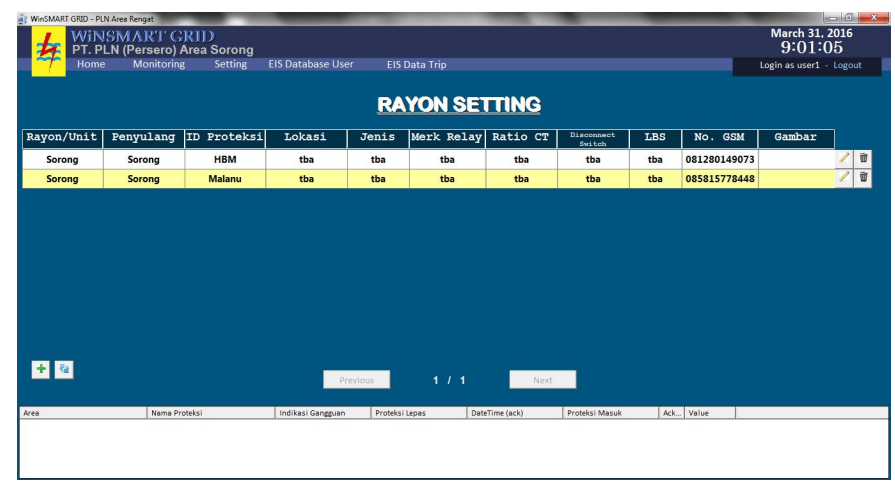

Gambar 3.8 Rayon Setting

Pada menu Setting ini, user dapat menambahkan titik proteksi baru dan dapat mengedit atau menghapus data titik proteksi yang sudah ada. Penambahan titik proteksi baru cukup dengan mengisi data-data yang diminta yang selanjutnya data titik proteksi baru itu akan muncul pada Menu Monitoring.

\section{TAMBAH RAYON}

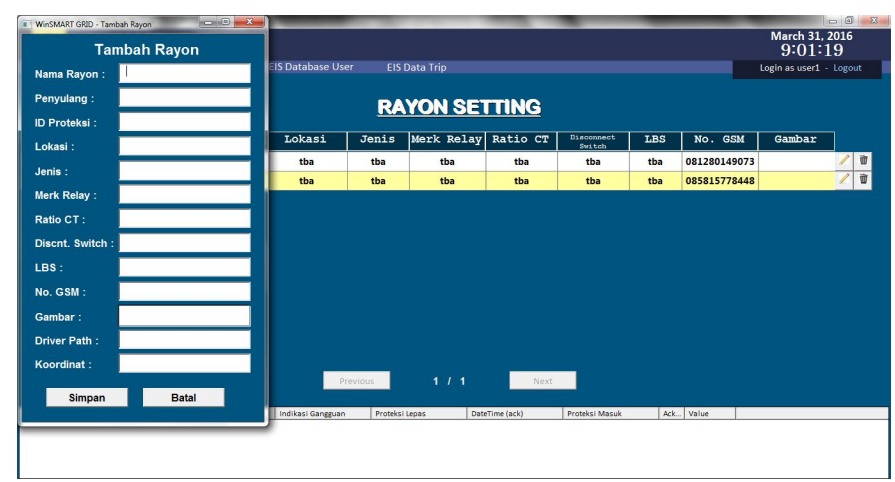

Gambar 3.9 Tambah Rayon

\section{DATABASE USER}

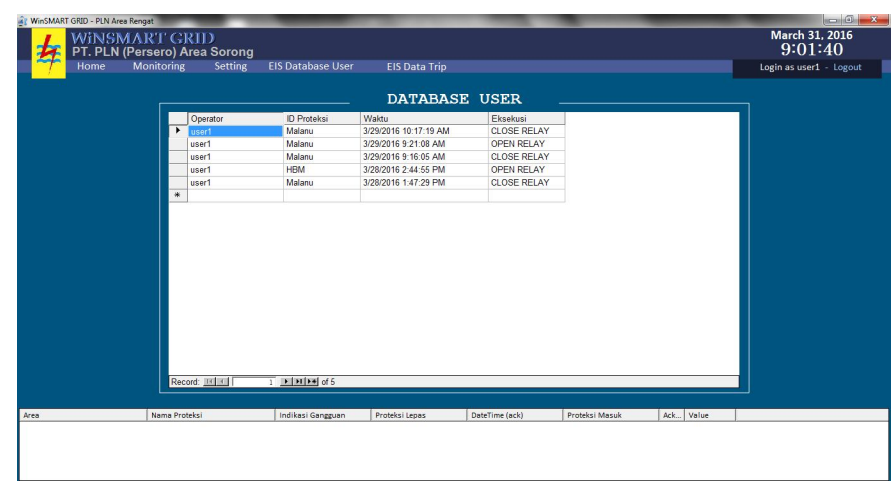

Gambar 3.10 Database User 
Dimana EIS data User ini berfungsi untuk mengetahui aktivitas yang dilakukan dalam mengeksekusi tombol open atau close di titik proteksi.

\section{DATA TRIP}

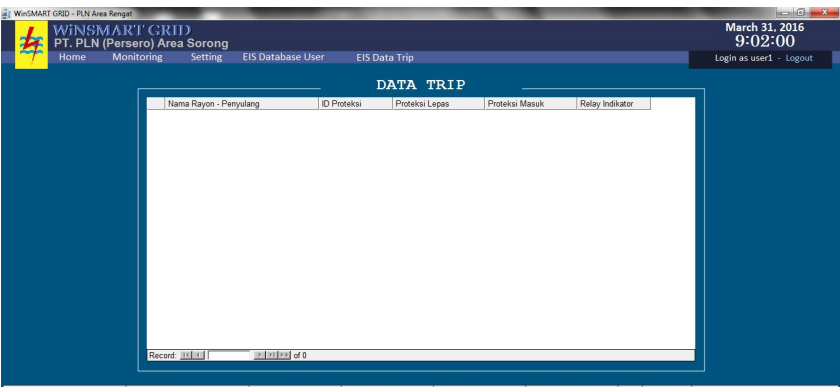

Gambar 3.11 Data Trip

Di dalam tabel EIS Data Trip ada beberapa kolom untuk merecord kegiatan yang dilakukan, diantaranya ID Pasword, Nama Proteksi, Waktu eksekusi open atau close, dan jenis eksekusi yang di laksanakan

\subsection{Pengambilan Data}

Pengambilan data dengan cara pilih menu monitoring pada aplikasi WinSMART GRID dan cari ID proteksi RecSimpang5.

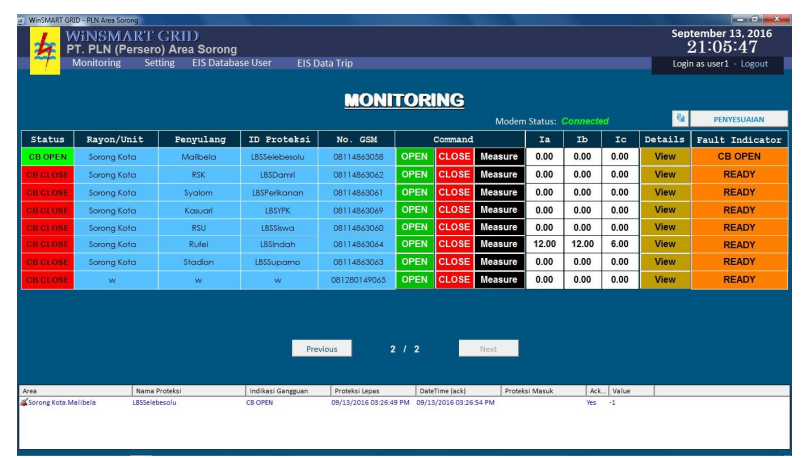

Gambar 3.12 Menu Monitoring

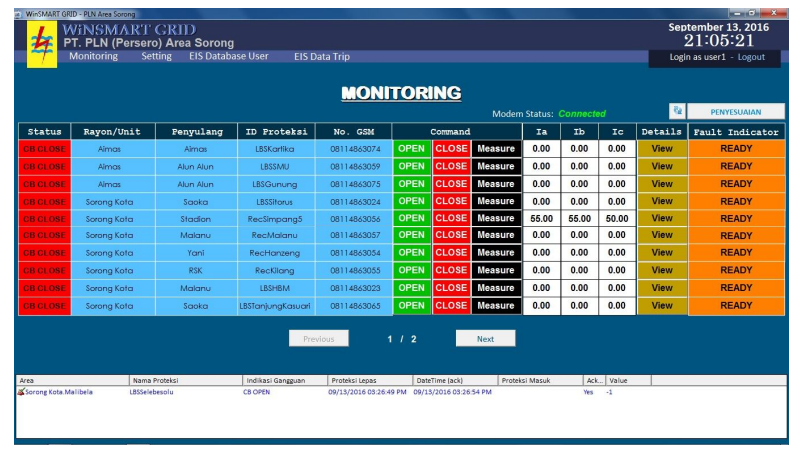

Gambar 3.13 Menu Monitoring

\section{ANALISA DAN PEMBAHASAN}

Untuk mengetahui apakah hasil dari penelitian ini, perlu dilakukan pengujian dan analisa terhadap data yang didapat. Dan sebagai bagian yang tak terpisahkan adalah proses evaluasi sehingga akan dilakukan langkah-langkah positif untuk menentukan hal terbaik dalam dunia kelistrikan.

4.1 Data Tampilan Monitoring Recloser Simpang 5 dan LBS PT PLN ( Persero ) Area Sorong

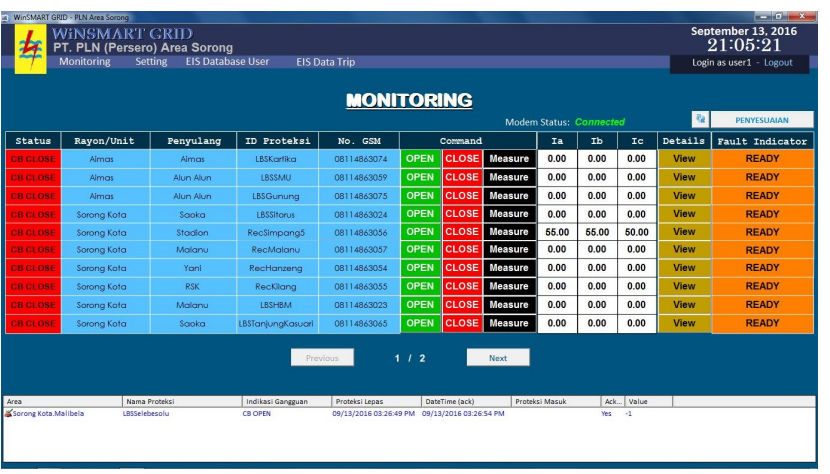

\section{Gambar 4.1 Monitoring}

Pada menu Monitoring ini recloser yang kita pantau yakni Recloser Simpang 5, dapat kita liat modem status connected dan user dapat memonitoring Recloser Simpang 5. status pemutus yaitu CB Close. User dapat mengeksekusinya dengan mengklik pada menu command Open/Close/Measure.

\subsection{Data Tampilan Single Line Diagram}

Penyulang Stadion ( Rec. Simpang 5 )

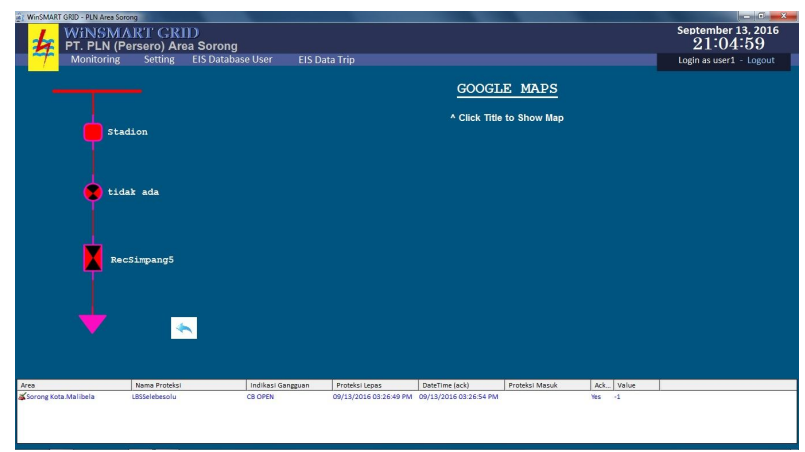

Gambar 4.2 Single Line 
Ditampilkan gambar single line dari Penyulang Stadion - LBS - Recloser Simpang 5, serta tampilan maps untuk mengetahui letak lokasi di setiap recloser.

\subsection{Data Tampilan Detil Rec. Simpang 5}

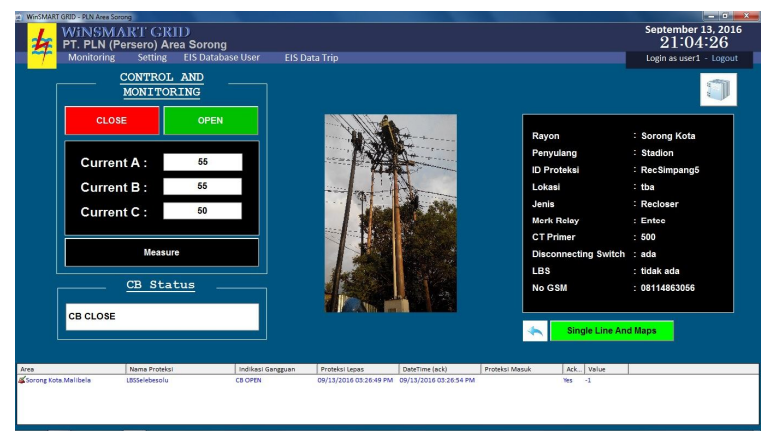

Gambar 4.3 Detil Recloser Simpang 5

Berikut tampilan detil Recloser Simpang 5, CB Status Close, Control and Monitoring Close/Open CB dan Arus A, B, C terlihat angka Arus A = 55 A, Arus B = $55 \mathrm{~A}$, Arus $\mathrm{C}=50 \mathrm{~A}$ dan terlihat detil penjelasan Recloser Simpang 5.

\subsection{Cara Kerja Recloser}

\subsubsection{Recloser Satu Fasa}

Recloser ini dipakai untuk pengaman saluran fasa, misalnya saluran cabang satu fasa dari saluran utama tiga fasa. Dapat juga di pakai saluran tiga fasa, dimana beban yang terbanyak adalah beban satu fasa, sehingga apabila terjadi ganguan menetap fasa tanah, maka hanya recloser pada fasa yang terganggu saja akan terus terbuka

\subsubsection{Recloser Tiga Fasa}

Recloser tiga fasa digunakan apabila pelepasan gangguan menetap. Keadaan untuk menghindari beban tiga fasa bekerja pada satu fasa. Dan umumnya recloser dengan tiga fasa digunakan pada gardu induk atau pada percabangan jaringan distribusi primer.

Recloser tiga fasa ini mempunyai dua cara kerja, yaitu:

1. Satu fasa membuka tiga fasa mengunci

Cara kerja seperti ini susunannya terdiri dari tiga unit recloser satu fasa yang ditempatkan dalam satu tangki, dan secara mekanis ketiganya di kopel untuk keadaan mengunci saja, sedangkan untuk membuka dan menutup kembali ketiga recloser itu bekerja pada fasanya masing- masing. Misalnya, jika salah satu fasa mengalami gangguan, maka recloser pada fasa itu saja bekerja sesuai dengan urutan kerjanya untuk melakukan operasi buka tutup. Sampai waktu kerjanya mengunci.

2. Tiga fasa membuka tiga fasa mengunci

Umumnya recloser dengan sistem kerja seperti ini digunakan pada jaringan distribusi tiga fasa. Untuk gangguan yang bersifat temporer maupun yang bersifat permanent akan menyebabkan kontak fasanya dapat membuka dan menutup kembali serta mengunci secara serentak. Dan biasanya recloser tiga fasa di lengkapi dengan peralatan pendeteksi gangguan fasa-fasa maupun gangguan fasa ke tanah. 


\subsection{Skema aplikasi WinSMART GRID}

Aplikasi WinSMART GRID merupakan aplikasi yang berbasis SMS Gateway, dibawah ini merupakan skema aplikasi WinSMART GRID.

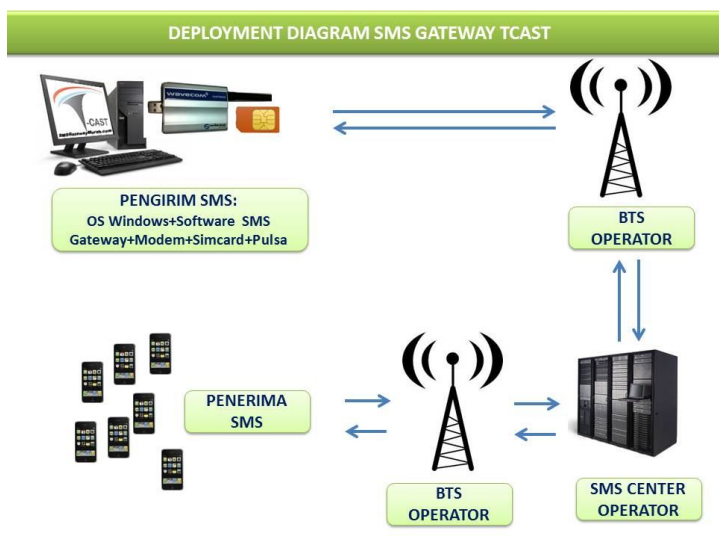

Gambar 4.4 Skema Aplikasi WinSMART GRID

\section{$5.1 \quad$ Kesimpulan}

Dengan memanfaatkan Recloser berbasis

SMS Gateway selain berfungsi sebagai alat pengaman terhadap gangguan terhadap arus, maka kombinasi dan gabungan dari pemakaian Recloser akan dapat meningkatkan keandalan pelayanan tenaga listrik kepemakai, karena masing - masing alat pengaman ini mempunyai kemampuan dan kerakteristik kerja sendiri - sendiri yang bila mana dipergunakan dengan tepat akan saling menunjang satu sama lain.

\subsection{Saran}

Mohon untuk ditinjau kembali Recloser berbasis SMS gateway, karena terlalu lama respon/feedbacknya melaksanakan commad yang diinginkan.

\section{DAFTAR PUSTAKA}

Drs. Ady Supriadi, SISTEM PENGAMAN TENAGA LISTRIK.

Djiteng Marsuli, Operasi SISTEM TENAGA

LISTRIK, edisi II. Graha Ilmu 2006.

Recloser. COOPER Power System. DISTRIBUSI

DAM UTILISASI TENAGA LISTRIK, ABDUL

Kadir.

Electrical Diatribution System Protektion.

COOPER POWER SYSTEMS. DR. A.

Arismunandar, Teknik Tegangan Listrik Jilid

II.1975.

Ir. Abdul Hadi. AS Pabla. SISTEM DISTRIBUSI

DAYA ISTRIK. 